\title{
Impact of maritime traffic on polycyclic aromatic hydrocarbons, metals and particulate matter in Venice air
}

\author{
Elena Gregoris $^{1,2}$ (D) Elena Barbaro ${ }^{1,2}$ - Elisa Morabito ${ }^{1,2}$ - Giuseppa Toscano ${ }^{1}$. \\ Antonio Donateo $^{3}$ - Daniela Cesari ${ }^{3} \cdot$ Daniele Contini $^{3}$ • Andrea Gambaro ${ }^{1,2}$
}

Received: 28 August 2015 / Accepted: 13 November 2015

(C) Springer-Verlag Berlin Heidelberg 2015

\begin{abstract}
Harbours are important hubs for economic growth in both tourism and commercial activities. They are also an environmental burden being a source of atmospheric pollution often localized near cities and industrial complexes. The aim of this study is to quantify the relative contribution of maritime traffic and harbour activities to atmospheric pollutant concentration in the Venice lagoon. The impact of ship traffic was quantified on various pollutants that are not directly included in the current European legislation for shipping emission reduction: (i) gaseous and particulate PAHs; (ii) metals in $\mathrm{PM}_{10}$; and (iii) $\mathrm{PM}_{10}$ and $\mathrm{PM}_{2.5}$. All contributions were correlated with the tonnage of ships during the sampling periods and results were used to evaluate the impact of the European Directive 2005/33/EC on air quality in Venice comparing measurements taken before and after the application of the Directive (year 2010). The outcomes suggest that legislation on ship
\end{abstract}

Responsible editor: Constantini Samara

Electronic supplementary material The online version of this article (doi:10.1007/s11356-015-5811-x) contains supplementary material, which is available to authorized users. traffic, which focused on the issue of the emissions of sulphur oxides, could be an efficient method also to reduce the impact of shipping on primary particulate matter concentration; on the other hand, we did not observe a significant reduction in the contribution of ship traffic and harbour activities to particulate PAHs and metals.

Keywords Ship traffic $\cdot$ Polycyclic aromatic hydrocarbons · Metals $\cdot$ Particulate matter $\cdot$ European legislation $\cdot$ Positive Matrix Factorization · Venice

\section{Abbreviations \\ POSEIDON (POllution monitoring of Ship EmissionAn IntegrateD approach fOr harbour of the Adriatic basiN)}

Daniele Contini

d.contini@isac.cnr.it

Andrea Gambaro

gambaro@unive.it

1 Department of Environmental Science Informatics and Statistics, Ca' Foscari University of Venice, Via Torino 155, Venice Mestre, Italy

2 Institute for the Dynamics of Environmental Processes, National Research Council, Via Torino 155, Venice Mestre, Italy

3 Institute of Atmospheric Science and Climate, National Research Council, Str. prov. Lecce-Monteroni km 1.2, Lecce, Italy 


$\begin{array}{ll}\text { PAHs } & \text { polycyclic aromatic hydrocarbons } \\ \text { PUF } & \text { polyurethane foam } \\ \text { QFF } & \text { quartz fiber filter } \\ \text { ACY } & \text { acenaphthylene } \\ \text { ACE } & \text { acenaphthene } \\ \text { FL } & \text { fluorene } \\ \text { PHE } & \text { phenanthrene } \\ \text { ANT } & \text { anthracene } \\ \text { FLT } & \text { fluoranthene } \\ \text { PYR } & \text { pyrene } \\ \text { BaA } & \text { benzo }[a] \text { anthracene } \\ \text { CHR } & \text { chrysene } \\ \text { BbF } & \text { benzo }[b] \text { fluoranthene } \\ \text { BkF } & \text { benzo[k]fluoranthene } \\ \text { BaP } & \text { benzo }[a] \text { pyrene } \\ \text { BghiP } & \text { benzo[ghi]perylene } \\ \text { IcdP } & \text { indeno[1,2,3-c, } d] \text { pyrene } \\ \text { DahA } & \text { dibenzo[a,h]anthracene } \\ \text { MAL } & \text { Malamocco } \\ \text { PS } & \text { Punta Sabbioni } \\ \text { SF } & \text { Sacca Fisola } \\ \text { PMF } & \text { Positive Matrix Factorization } \\ \text { PCA } & \text { Principal Component Analysis } \\ \text { HCA } & \text { Hierarchical Cluster Analysis } \\ \end{array}$

\section{Introduction}

Harbours are important hubs for economic growth in both tourism and commercial activities. They are also an environmental burden being a source of atmospheric pollution often localized near cities and industrial complexes. This is particularly true considering that, at a global level, even though land-based emissions of airborne pollutants are decreasing; ship emissions are increasing, leading to potential negative effects on health, climate and social welfare (EEA 2013). In the last decades, international legislation focused on the pollution generated by maritime traffic, gradually reducing the emissions associated to this type of transport. The International Convention for the Prevention of Pollution from Ships (MARPOL) is the main international convention covering prevention of pollution of the marine environment by ships. The Annex VI "Prevention of Air Pollution from Ships" entered into force on 19 May 2005 and is now ratified by 80 states/parties, covering $95 \%$ of the world tonnage. MARPOL introduced also the concept of Emission Control Areas (ECAs), which have more stringent standards; they include the Baltic Sea area, the North Sea area, the North American area and the United States Caribbean Sea area (ECG 2014; IMO 2015, 2015). In Europe, the requirements concerning the sulphur content of gas oils appeared in the Directive 1999/32/ EC, amended by the Directives 2005/33/EC and 2012/33/EU. In the Venice lagoon, the area considered in this study, a voluntary agreement called Venice Blue Flag (VBF), was signed in 2007 and 2008. Overall, the major improvement was applied to fuels during berth, which passed from $4.5 \%$ of sulphur allowed, with no difference between berth and navigation, to $2.0-2.5 \%$ (2007-2009) under the VBF and even to $0.1 \%$ after 1 January 2010 (Directive 2005/33/EC). A summary of the limits of sulphur content in marine fuels, concerning the area of Venice, is reported in Contini et al. (2015). The modification of the sulphur standard led to the expected decrease in the emission of sulphur oxides, clearly visible when analyzing air samples collected before and after 1 January 2010 in the Mediterranean (Schembari et al. 2012). A significant decrease in the particulate matter produced by ship traffic was also observed in the Venice lagoon (Contini et al. 2015), but evaluations regarding the effect of the legislation on polycyclic aromatic hydrocarbons and metals concentrations are missing. This work was carried out in the framework of the POSEIDON project (POllution monitoring of Ship Emission: an IntegrateD approach fOr harbour of the Adriatic basiN), whose aim is to quantify the relative contribution of maritime traffic and harbour activities to atmospheric pollutants concentration in four port cities of the Adriatic Sea (Brindisi, Venice, Patras and Rijeka), starting from available emission inventories in the four cities. Among the objectives of the POSEIDON project, there is also the identification of policy gaps and the support in proposing integrated common strategies for sustainable development of the coastal area of the Adriatic Sea. The present study focuses on the port city of Venice. The ship traffic impact was quantified on various pollutants not directly included in the current legislation on shipping emissions: (i) gaseous and particulate PAHs; (ii) metals in $\mathrm{PM}_{10}$; and (iii) $\mathrm{PM}_{10}$ and $\mathrm{PM}_{2.5}$. The quantification was conducted on data collected from 2007 (or 2009) to 2013 in order to evaluate the effect of the changing legislation on the Venice lagoon, as well as the environmental situation of the studied area over the last decade.

\section{Material and methods}

\section{Polycyclic aromatic hydrocarbons}

\section{Reagents and materials}

Pesticide-grade dichloromethane, $n$-hexane and toluene (Romil Ltd., UK) were used. All isotope-labelled standard solutions (CLM-2477, CLM-2722, CLM-3757 and CLM-2451) were acquired from CIL (Cambridge Isotope Laboratories Inc., USA); the PAH native standard solution (PAH Mix 9) was purchased from Dr. Ehrenstorfer $\mathrm{GmbH}$ (Germany). All the tools and glassware were washed $v / v$ Contrad solution (Decon Laboratories Limited, UK), dried and rinsed with dichloromethane and $n$-hexane before use. 
Sampling and analysis

Overall, twenty-two samples were collected in the Sacca San Biagio island $\left(45^{\circ} 25^{\prime} 40.1^{\prime \prime} \mathrm{N}, 12^{\circ} 18^{\prime} 36.7^{\prime \prime} \mathrm{E}\right)$, which is located along the Giudecca Canal, $1 \mathrm{~km}$ from the tourist harbour, in two different campaigns (summer 2009 and summer 2012). A map of the studied area is shown in Fig. 1; the dates of the sampling campaigns are reported in Table A1. Two high-volume air samplers AirFlowPUF $\left(0.3 \mathrm{~m}^{3} / \mathrm{min}\right.$; Analitica Strumenti, Italy) were used. One of the two samplers was used in the classic mode, collecting air from all the directions; the second one was conditioned by the wind direction: it was programmed to turn on when the wind was blowing from the sector NW-NE $315^{\circ}-45^{\circ}$ (speed $>1 \mathrm{~m} / \mathrm{s}$ ), which is the direction of the harbour. This technique permits to investigate the differences in PAH concentration associated to aerosol from the harbour with respect to the average concentration. Gaseous PAHs were collected on pre-cleaned polyurethane foams (PUFs, height $75 \mathrm{~mm}$, diameter $65 \mathrm{~mm}$, SKC Inc.) and PAHs in particulate phase on pre-combusted quartz fibre filters (QFFs, porosity $1 \mathrm{um}$, size $102 \mathrm{~mm}$, SKC Inc.). The cleaning procedure was described elsewhere (Gregoris et al. 2014). PUFs and QFFs were replaced every 2-3 days. After sampling, QFFs and PUFs were stored a $-20{ }^{\circ} \mathrm{C}$ until extraction. Field blanks were used to determine any contamination during sample handling and preparation. Extraction and purification of PUFs and QFFs samples was conducted using automatic systems (Pressurized Liquid Extractor and PowerPrep, Fluid Management System Inc., USA), as described in Donateo et al. (2014). For quantitative purposes, three ${ }^{13} \mathrm{C}$-labelled PAHs $\left({ }^{13} \mathrm{C}\right.$-acenaphthylene, ${ }^{13} \mathrm{C}$-phenanthrene and ${ }^{13} \mathrm{C}$-benzo[a]pyrene) were spiked before extraction; ${ }^{13} \mathrm{C}$-chrysene was added after purification and used as recovery standard. Samples were analyzed by high-resolution gas chromatography (7890A, Agilent Technologies, USA), coupled with quadrupole mass spectrometry (5975C, Agilent Technologies). The gas-chromatograph operating conditions are reported in Gregoris et al. (2014). Fifteen of the priority PAHs, as indicated by the US Environmental Agency, were determined as follows: acenaphthylene (ACY), acenaphthene (ACE), fluorene (FL), phenanthrene (PHE), anthracene (ANT), fluoranthene (FLT), pyrene (PYR), benzo $[a]$ anthracene (BaA), chrysene (CHR), benzo[b]fluoranthene $(\mathrm{BbF})$, benzo[ $k]$ fluoranthene (BkF), benzo $[a]$ pyrene (BaP), benzo $[$ ghi $]$ perylene (BghiP), indeno[1,2,3-c,d]pyrene (IcdP) and dibenzo $[a, h]$ anthracene (DahA). The limit of detection (LOD) was calculated from the mean blank value plus three standard deviations. PUF and QFF samples concentration that were above the LOD were corrected for the corresponding average field blank. The accuracy of the analytical method was tested by Piazza et al. (2013).

\section{Data elaboration}

The coefficient $\chi$ (Donateo et al. 2014) was used to evaluate the percentage of PAHs coming from the harbour sector, compared to pollutants coming from all directions. For both sectors (harbour sector NW-NE $315^{\circ}-45^{\circ}$ and the other sector $\mathrm{NE}-\mathrm{NW} 45^{\circ}-315^{\circ}$ ), every contribution to the PAH concentration is normalized for the effective sampling time.

$\chi(\%)=\frac{\frac{Q_{H}}{h_{H}}}{\frac{Q_{H}}{h_{H}}+\frac{Q_{360}-Q_{H}}{h_{360}-h_{H}}} \cdot 100$

where: $\mathrm{Q}_{\mathrm{H}}$ is the PAH quantity (ng) in aerosol coming from the harbour sector (NW-NE $315^{\circ}-45^{\circ}$ ); $\mathrm{h}_{\mathrm{H}}$ is the sampling time (h) for which the wind-select samplers was operating. $\mathrm{Q}_{360}$ is the PAH quantity in aerosol coming from all directions; $\mathrm{h}_{360}$ is the sampling time (h) of the other sampler, collecting air at $360^{\circ}$. The coefficient $\chi$ takes into account the variability of wind strength and direction in different campaigns, but it is still a site-dependent value. It can be applied to the total PAH concentration (sum of the 15 congeners analyzed) or to single congener concentration. In order to improve the quantitative comparison of the contribution, limiting the effects of ship traffic variability, results were normalized using the real ship traffic during the sampling (tonnage, in ktons), whose data were kindly provided by the Venice Port Authority. In order to consider to total tonnage, we calculated the sum of the tonnage of all the ships which have been docked at the tourist harbour during the sampling period.

\section{Metals in $\mathbf{P M}_{10}$}

\section{Reagents and materials}

High-purity de-ionized water (18 $\mathrm{M} \Omega \mathrm{cm}^{-1}$ resistivity) was produced using a Purelab Ultra unit, (Elga, High Wycombe, UK). Ultrapure nitric acid, fluoridric acid and hydrogen peroxide (Romil Ltd., UK) were used. All elemental standard solutions (IMS102, ICP051 and ICP042) were acquired from Ultrascientific (USA).

\section{Sampling and analysis}

Daily $\mathrm{PM}_{10}$ samples were collected in three sites around the lagoon, shown in Fig. 1. Two of them are located near the lagoon inlets. Specifically: Malamocco (MAL; 45 $20^{\prime} 00.2^{\prime \prime N}$ $\left.12^{\circ} 19^{\prime} 07.9^{\prime \prime} \mathrm{E}\right)$ is located near the lagoon inlet dedicated to commercial ships and Punta Sabbioni (PS; 45 $26^{\circ} 22.3^{\prime \prime N}$ $12^{\circ} 25^{\prime} 18.9^{\prime \prime} \mathrm{E}$ ) is near the inlet usually used by cruises to enter the lagoon. In these two sites, samples were collected from 2007 to 2013 in the course of several campaigns (generally 


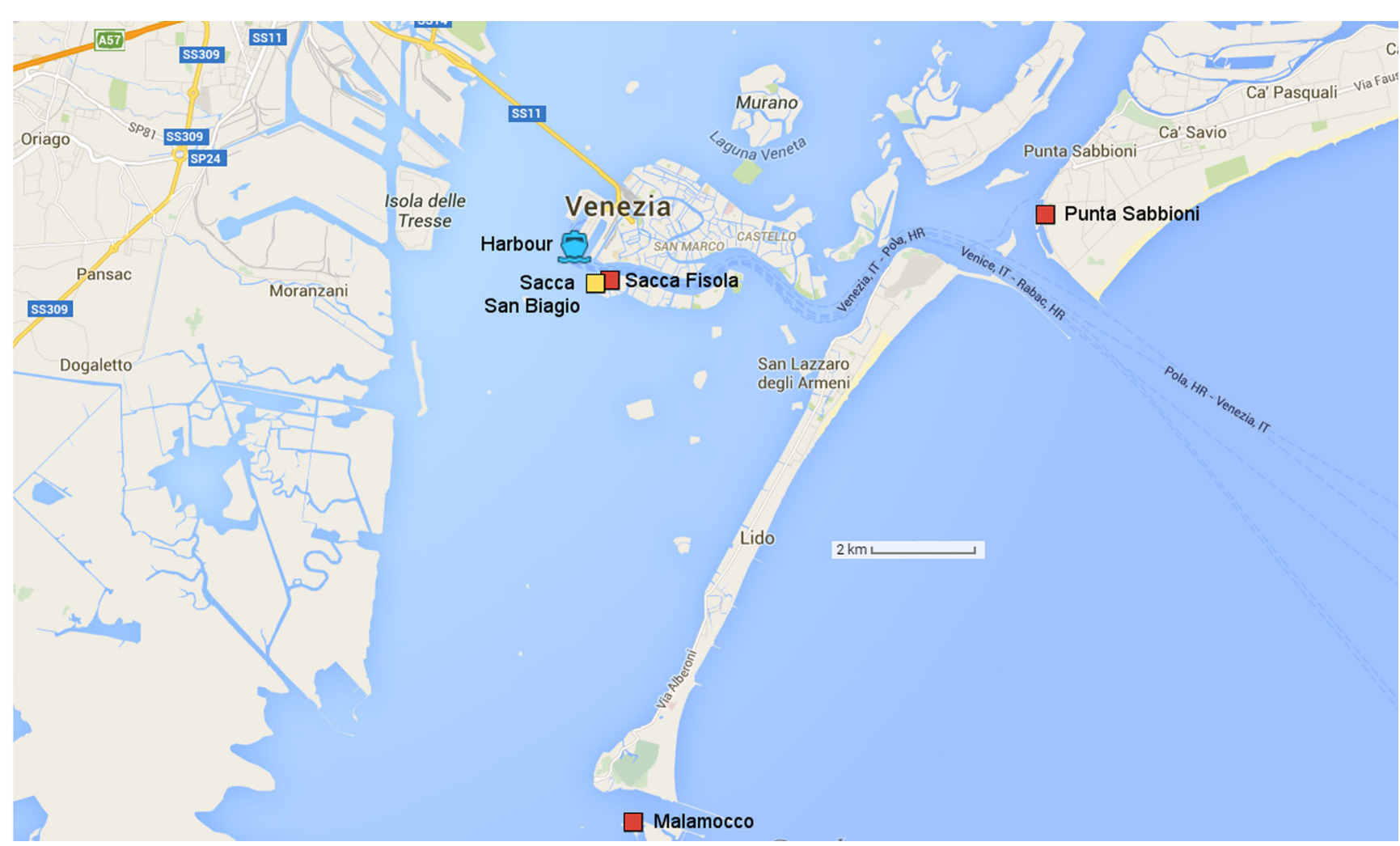

Fig. 1 Sampling site for $\mathrm{PM}_{10}$ (red squares) and PAHs (yellow square)

lasting 2 weeks), distributed to cover the different seasons: overall, 242 and 220 samples were collected in MAL and PS, respectively. The third site (Sacca Fisola, SF; $45^{\circ}$ $\left.25^{\prime} 41.6^{\prime \prime} \mathrm{N} 12^{\circ} 18^{\prime} 46.7^{\prime \prime} \mathrm{E}\right)$ is located along the Giudecca Canal, on the opposite side of the tourist harbour. Overall, $1143 \mathrm{PM}_{10}$ samples were collected from 2009 to 2013. Data of metals and $\mathrm{PM}_{10}$ concentrations in SF were kindly provided by the Regional Agency for the Prevention and Protection of the Environment of Veneto (ARPAV). The dates of the sampling campaigns are reported in the Online Resource (Table A1). The instrumentation used for the sampling was a low-volume aerosol sampler (38.33 1/min; Skypost PMHV, TCR Tecora, France). $\mathrm{PM}_{10}$ was collected on quartz fiber filters (Sartorius, diameter $47 \mathrm{~mm}$ ); two of sixteen filters were used as field blanks. Blank and sample filters were weighed three times (\%RSD $0-0.1 \%$ ) over $24 \mathrm{~h}$ before and after the sampling using a Sartorius Competence CP64-0CE balance (precision of $0.01 \mathrm{mg}$ ). The balance and the filters were kept at controlled temperature $\left(18 \pm 3{ }^{\circ} \mathrm{C}\right)$ and humidity $(51 \pm 3 \%)$, before and during the weighing procedure. Each filter was then microwave-digested (Ethos1-Milestone), with $6 \mathrm{~mL} \mathrm{HNO}_{3}$, $3 \mathrm{~mL} \mathrm{H}_{2} \mathrm{O}_{2}$, and $1 \mathrm{~mL} \mathrm{HF}$ (Romil ${ }^{\circledR}$ UPA). The digestion temperature programme consisted of a ramp from room temperature to $190{ }^{\circ} \mathrm{C}$ in $25 \mathrm{~min}$, after which this value was maintained for $15 \mathrm{~min}$. One or two blank samples containing the same amount of individual acids were routinely prepared for simultaneous digestion. The cleaning procedure was reported in Contini et al. (2012). Metals (V, Cr, Fe, Co, Ni, $\mathrm{Cu}, \mathrm{Zn}, \mathrm{As}, \mathrm{Mo}, \mathrm{Cd}, \mathrm{Sb}, \mathrm{Tl}, \mathrm{Pb}$ ) in $\mathrm{PM}_{10}$ samples were measured by Inductively Coupled Plasma-Quadrupole Mass Spectrometry (ICP-QMS 7500I, Agilent Technologies). The LOD was calculated from the mean blank value plus three standard deviations. Element concentrations, when above the LOD, have been obtained after subtraction of their field blank values. Recoveries were evaluated using standard reference material (NIST 1648a), and were: $\mathrm{V}(114 \%), \mathrm{Cr}(81 \%), \mathrm{Fe}$ (121\%), Co (117\%), Ni (121\%), Cu (103\%), Zn (84\%), As (100\%), $\mathrm{Cd}(92 \%), \mathrm{Sb}(72 \%)$ and $\mathrm{Pb}(112 \%)$.

\section{Positive matrix factorization}

To identify the possible sources of $\mathrm{PM}_{10}$ the Positive Matrix factorization (PMF) method was adopted (EPA PMF 3.0 software). Data were preliminarily refined in order to obtain a more robust dataset. Variables with more than $50 \%$ of missing values or $50 \%$ of values under the LOD were rejected, with the exception of those variables that could be considered as tracers for specific sources (i. e. vanadium for ship traffic). Outliers have been identified and excluded, based on the quartile test. Missing values were replaced by the median of the values, while values under the LOD were substituted by half of the LOD. As uncertainty, the standard deviations of the method, normalized for the average sampling volumes of each campaign, were used. The uncertainty of missing values was 
four times the median value; the uncertainty of values under the LOD was 5/6 LOD. In order to individuate the right number of factors different solutions were explored; the parameters IM (maximum of the average of the scaled residual) and IS (maximum of the standard deviation of the scaled residuals), together with the Q value were examined, following the approach reported in Contini et al. (2012). Different running were also performed for multiple values of the peak coefficient ( $\mathrm{F}_{\text {peak }}$ between -1.0 to 1.0, with steps of 0.2). The uncertainty of PMF results was obtained using the bootstrap method (100 runs). Since the total metals analyzed represent a very small percentage (around $1.3 \%$ ) of total $\mathrm{PM}_{10}$ a source apportionment in $\mathrm{PM}$ is not possible. Therefore the $\mathrm{PM}_{10}$ mass was not included as total variable in the datasets and the source apportionment was conducted to the sum of the metals analyzed. Once a factor was associated to maritime traffic, the contribution of the factor was normalized for the ship traffic (tonnage, in ktons). In order to consider to total tonnage we calculated the sum of the tons of all the ships which passed near the sampling site during the sampling period. To improve the understanding of the profiles found by PMF, Principal Component analysis (PCA) and Hierarchical Cluster Analysis (HCA) were performed on each dataset, using the Statistica 8.0 software (Statsoft Inc., USA). PCA was performed using varimax rotation and HCA using the Ward's Method (Square Euclidean Distance).

\section{Calculation of primary contribution to PM}

The primary contribution of ship traffic to $\mathrm{PM}_{2.5}$ can be evaluated using atmospheric vanadium as tracer for ship traffic and by applying the equation (2), first introduced by Agrawal et al. (2009).

$\mathrm{PM}_{\text {ship }}\left(\mu \mathrm{g} / \mathrm{m}^{3}\right)=\frac{R \cdot V_{\mathrm{a}}}{F_{V, \mathrm{HFO}}}$

The value of the constant $R$ suggested in Agrawal et al. (2009) is 8205.8. It is a value universally adopted in location with heavy fuel oil burning ship emissions (Cesari et al. 2014; Zhao et al. 2013). $V_{\mathrm{a}}$ is the ambient vanadium concentration $\left(\mu \mathrm{g} / \mathrm{m}^{3}\right) ; F_{\mathrm{V}}$, HFO is a term indicating the typical $V$ content (ppm) in heavy fuel oils (HFO) used by vessels: this term depends on the fuel used and it presents a large variability. The content of $\mathrm{V}$ in the fuel could be obtained from specific data regarding ship travelling in the area or from typical values relative to each typology of ships (Zhao et al. 2013). In this work the authors applied the equation (2) to evaluate the contribution to $\mathrm{PM}_{10}$ : a value of $65 \pm 25 \mathrm{ppm}$ was used, as done for the Brindisi harbour (Cesari et al. 2014). The obtained $\mathrm{PM}_{\text {ship }}\left(\mu \mathrm{g} / \mathrm{m}^{3}\right)$ was converted in percentage dividing for the $\mathrm{PM}_{10}$ corresponding value and then normalized by the ship traffic (tonnage, in ktons). In order to consider the total tonnage we calculated the sum of the tonnage of all the ships which passed near the sampling site during the sampling period.

\section{Results and discussion}

\section{Polycyclic aromatic hydrocarbons}

\section{Levels of PAHs}

In general, air coming from the harbour sector was characterized by a higher total PAH content (average values of $30.7 \mathrm{ng} /$ $\mathrm{m}^{3}$ in 2009 and $6.3 \mathrm{ng} / \mathrm{m}^{3}$ in 2012, for gas and particulate PAHs together, respectively), with respect to the air of the city $\left(5.4 \mathrm{ng} / \mathrm{m}^{3}\right.$ and $2.6 \mathrm{ng} / \mathrm{m}^{3}$, in 2009 and 2012, respectively). The same effect was observed in Brindisi by applying the same double-sampling method (Donateo et al. 2014). A decrease in the total PAH concentration was observed between 2009 and $2012(-52 \%$ in ambient air; $-79 \%$ in air from the harbour), as shown in the Online Resource (Figure A1). PAHs were predominant in gaseous form: PAHs in gaseous phase accounted for $73 \%$ (in 2009) and $85 \%$ (in 2012) of total PAHs in the $360^{\circ}$ sampling; in the harbour sector they represented about $80 \%$ of total PAHs. Single congener concentration ranged from a few $\mathrm{pg} / \mathrm{m}^{3}$ to a few $\mathrm{ng} / \mathrm{m}^{3}$. The main contributors to the total concentration were PHE, FLT and PYR, representing from 52 to $81 \%$ of $\Sigma \mathrm{PAHs}$, counted together. Gaseous phase was dominated by low molecular weight PAHs, in particular by ACE, FL, PHE, FLT and PYR; PAHs with five or six aromatic rings were mainly present in particulate matter. A similar profile was observed in other studies (Cincinelli et al. 2007; Hassan and Khoder 2012): low molecular weight PAHs are generally more volatile than high molecular weight PAHs, and are therefore more likely to be found in gaseous phase.

\section{Contribution of the harbour sector to PAHs}

Equation (1) was first applied to total PAH values, including both gaseous and particulate phases. The contribution of the harbour sector to ambient concentration was stable over the years: averages of $82 \%(74-90 \%)$ in 2009 and $82 \%$ (76$94 \%$ ) in 2012, with the inter-quartile range in brackets. These values are higher than that obtained for Brindisi using the same method (Donateo et al. 2014). As we mentioned in paragraph 3.1.1., the concentration of PAHs decreased as time passed both in the harbour sector and in the other directions, resulting in a stable contribution of the harbour sector to the ambient PAH concentration. In order to make a better comparison between campaigns with different ship traffic, the normalized contribution of the harbour was reported: it was $75 \%$ (67-82 \%)/Mtons in 2009 and $64 \%$ (59-73\%)/Mtons in 2012 
(Fig. 2a). Given that the maritime traffic increased in the sampling period from 2009 to 2012 (from 324 ktons/day to $373 \mathrm{ktons} /$ day) and the absolute contribution remained stable, actually there was a small reduction in the normalized contribution of ships to the ambient PAH concentration. The same equation was applied separately to gaseous and particulate PAHs (sum of the fifteen congeners). Results are reported in Fig. 2a; they show a little decrease of the contribution to the gaseous phase (from $74 \%(68-82 \%$ )/Mtons in 2009 to $63 \%$ (61-72\%)/Mtons in 2012) and an essentially stable value for particulate PAHs: $53 \%$ (49-65 \%)/Mtons (in 2009) and $52 \%$ (37-67\%)/Mtons (in 2012). Despite the limited number of samples, the outcomes suggest that legislation on mitigation of ship traffic emissions, which entered in force between the two investigated periods, had little influence on PAHs, with respect to what has been observed for primary particulate matter in previous studies on Venice (Contini et al. 2015).

\section{Metals in $\mathbf{P M}_{10}$}

\section{Levels of $P M_{10}$ and metals}

The average concentration of $\mathrm{PM}_{10}$ was $35 \mu \mathrm{g} / \mathrm{m}^{3}$ in MAL, $36 \mu \mathrm{g} / \mathrm{m}^{3}$ in PS and $31 \mu \mathrm{g} / \mathrm{m}^{3}$ in SF, with no significant trend passing from 2007 to 2013. Concentration of metals in $\mathrm{PM}_{10}$ ranged from a few $\mathrm{ng} / \mathrm{m}^{3}$ to around $0.3 \mu \mathrm{g} / \mathrm{m}^{3}$ for iron. The metals profiles, shown in the Online Resource (Figure A2), are similar in the three sites: iron and zinc were the most abundant elements $\left(\mathrm{Fe}: 290 \mathrm{ng} / \mathrm{m}^{3}\right.$, $324 \mathrm{ng} / \mathrm{m}^{3}, 274 \mathrm{ng} / \mathrm{m}^{3}$ and $\mathrm{Zn}: 41 \mathrm{ng} / \mathrm{m}^{3}, 46 \mathrm{ng} / \mathrm{m}^{3}$, $98 \mathrm{ng} / \mathrm{m}^{3}$ in MAL, PS and SF respectively). A specific temporal trend of metal concentrations was not observed. The species analyzed represented from $1.1 \%$ to $1.3 \%$ of total $\mathrm{PM}_{10}$.

\section{Contribution of ship traffic to metals in $P M_{10}$}

The characterization of the possible sources of metals in $\mathrm{PM}_{10}$ was conducted applying the PMF technique, following the approach previously described. After the preliminary dataset refining, nine variables were chosen as input for the model: $\mathrm{V}$, $\mathrm{Cr}, \mathrm{Fe}, \mathrm{Ni}, \mathrm{Cu}, \mathrm{Zn}, \mathrm{As}, \mathrm{Cd}$ and $\mathrm{Pb}$. The number of samples was 187 for MAL, 212 for PS and 1125 for SF. All datasets were considered good for the receptor model. According to the EPA PMF3 guide, PMF is often used for datasets with over 100 samples; moreover these datasets respect the suggestions by Henry et al. (1984) (ratio between degrees of freedom and number of variables higher than 100) and by Thurston and Spengler (1985) (number of samples exceed the number of variables by at least a factor of three). Therefore we could apply PMF to each dataset separately. The PMF data handling require a discrimination of "strong", "weak" and "bad" variables, according to the signal to noise $(\mathrm{S} / \mathrm{N})$ ratio criterion, the residual analysis and evaluating the observed/predicted scatter plots. In this work the following conditions were chosen: $\mathrm{Cu}$ and $\mathrm{Cd}$ were set as "strong" in all the datasets; $\mathrm{V}, \mathrm{Ni}$ and $\mathrm{Pb}$ were set as "strong" for MAL and PS and "weak" for SF; Cr and Fe were "strong" for PS and SF and "weak" for MAL; Zn was "strong" for PS and "weak" for the other datasets; As was set as "strong" for SF and "weak" for MAL and PS. An additional uncertainty (5 \% for MAL; $10 \%$ for PS and SF) was included for all the species. These values take into account various errors not considered before, such as laboratory errors, profile variations and chemical transformation in the atmosphere. The most reasonable solutions were obtained with 4 factors and with $\mathrm{F}_{\text {peak }}=0$ in all the sites (Fig. 3). In MAL and PS the reconstruction of the model was good $\left(R^{2}\right.$ was 0.76 for MAL and 0.89 for PS); the identified factors were very similar in the two sites and were coherent with a previous study in the same study area (Contini et al. 2012).

- The first factor was associated with the glass industry, because of the high contribution of Cd and As; Rampazzo et al. (2008) reported that particles released by glass factories in Venice area were characterized by $\mathrm{Cd}$, As and $\mathrm{Se}$.

- The second factor was characterized by $\mathrm{V}$ and $\mathrm{Ni}$, which are the typical markers for fossil fuel combustion. In order to better characterize this factor the $\mathrm{V} / \mathrm{Ni}$ ratio was

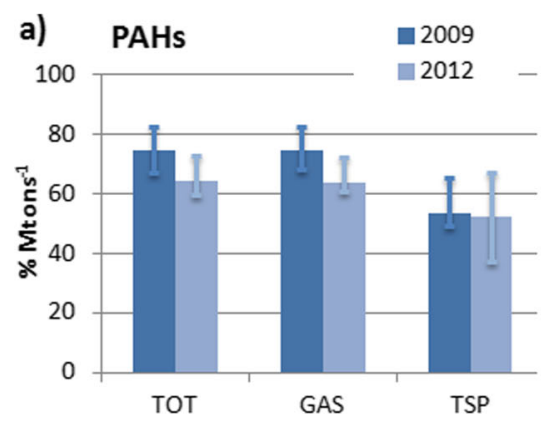

Fig. 2 Normalized contribution of ship traffic to: (a) polycyclic aromatic hydrocarbons (PAHs), evaluated using a double-sampling method and applying Equation 1. Error bars represent the inter-quartile range; (b) metals in $\mathrm{PM}_{10}$, using the contributions of the fossil fuel combustion
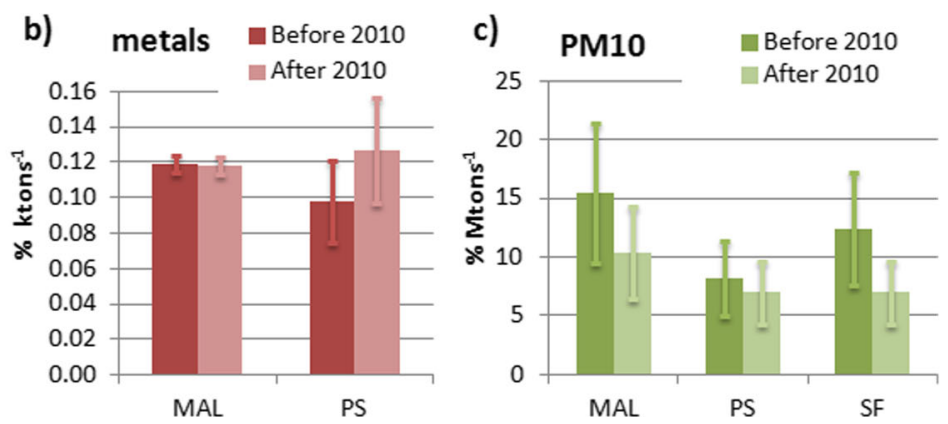

source, obtained using the positive matrix factorization (PMF) technique; (c) $\mathrm{PM}_{10}$, calculated applying equation (2). TOT gaseous plus particulate phase, GAS gaseous phase, TSP total suspended particulate, $M A L$ Malamocco, $P S$ Punta Sabbioni, SF Sacca Fisola 


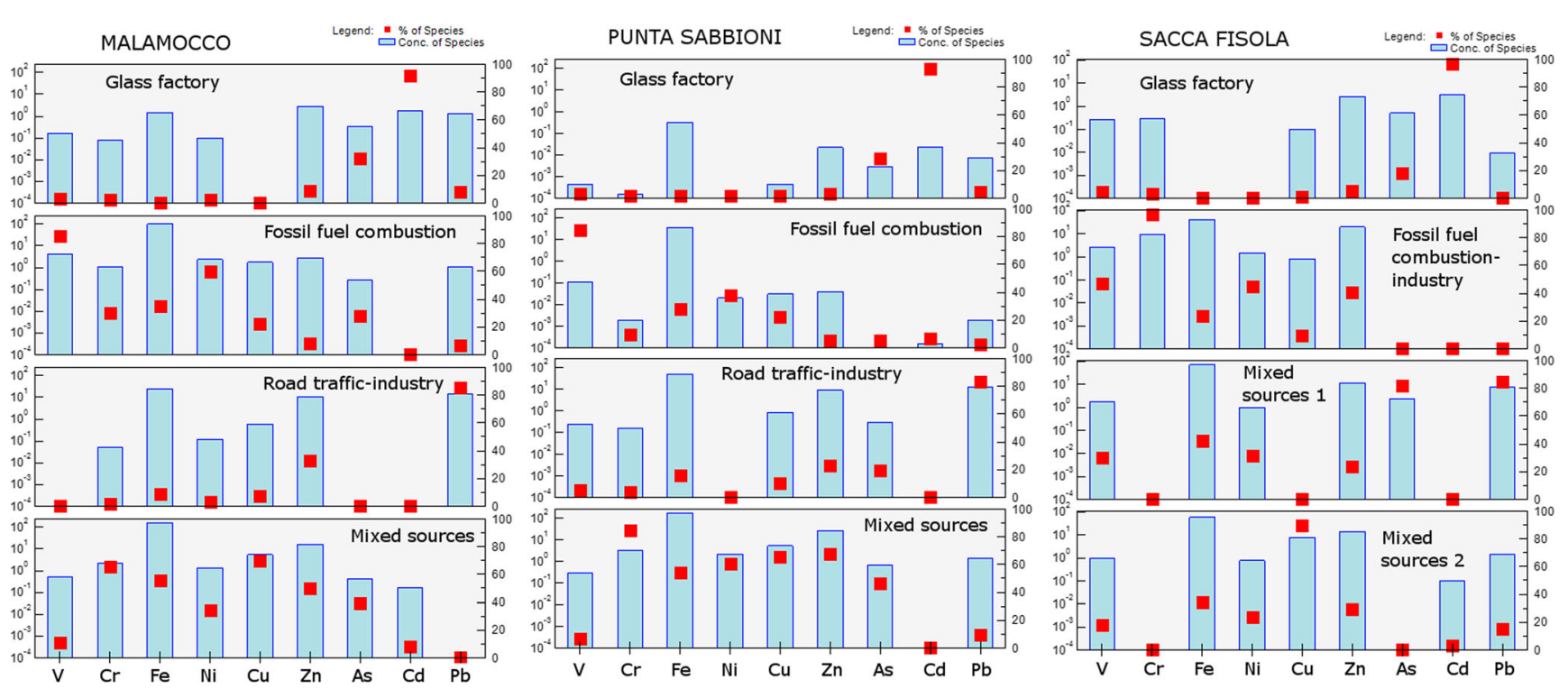

Fig. 3 Factor source profiles identified by PMF, for the three sites. Concentrations of species are expressed both as absolute (ng/ $\mathrm{m}^{3}$, left vertical axis) and relative concentrations $(\%$, right vertical axis)

calculated: V/Ni was 2.0 for MAL and 3.2 for PS. Viana et al. (2009) established V and Ni as valid tracers of shipping emissions, with a typical V/Ni ratios of 2.5-3.0, specifically for the Mediterranean harbours; for this reason, even when maintaining this factor associated to fossil fuel combustion (that could originate from industries or ship emission), an important contribution of ship traffic was expected.

- Another factor was mainly defined by $\mathrm{Pb}$ and $\mathrm{Zn}$, which are tracers of traffic emission (Cesari et al. 2014), but could also be present in industrial emissions.

- The last factor was characterized by different elements, both from crustal $(\mathrm{Fe})$ and anthropogenic origin $(\mathrm{Cr}, \mathrm{Ni}$, $\mathrm{Cu}, \mathrm{Zn}, \mathrm{As}) . \mathrm{Cr}$, $\mathrm{Ni}$ and As could have industrial origin, $\mathrm{Cu}$ and $\mathrm{Zn}$ could originate from road traffic, but it not possible to exclude also a contribution from glass factories. Therefore, the factor could not be associated to a specific source, and was considered a mixed source.

PCA was performed to improve our knowledge about the sources of metals in Venice. A component characterized by high loadings of $\mathrm{V}$ and $\mathrm{Ni}$ was identified in both MAL (loadings of 0.93 for $\mathrm{V}$ and 0.75 for $\mathrm{Ni}$ ) and in PS (loadings of 0.94 for $\mathrm{V}$ and 0.52 for $\mathrm{Ni}$ ) datasets. That component was associated to the fossil fuel combustion source. The correlation coefficient between the contributions of the fossil fuel combustion factor (by PMF) and the loadings related to the corresponding principal component (by PCA) revealed a very high correlation between the results (0.98 in MAL and 0.96 in PS). We observed that also the other factors matched well with the principal components, with correlation coefficient always above 0.87 , confirming the validity of the PMF results (Online
Resource, Table A3). Cluster analysis, performed on MAL and PS datasets highlighted a short linkage distance between vanadium and nickel (Online Resource, Figure A3), suggesting a common origin of the two variables.

As previously mentioned, since the total elements analyzed represent a very small percentage of $\mathrm{PM}_{10}$, in this work sources were apportioned towards the total metals analyzed. The contribution of the fossil fuel combustion factor was 24 $\pm 1 \%$ for MAL and $35 \pm 8 \%$ for PS. The source apportionment was also conducted by separating data collected before and after 1 January 2010 and these values were then normalized for the effective ship traffic during the sampling period (Fig. 2b). In MAL no significant change was observed considering the uncertainties $(0.119 \pm 0.005 \% / \mathrm{ktons}$ before 2010 and $0.118 \pm 0.005 \% / \mathrm{kMtons}$ from 2010$)$; in PS the normalized contribution increased from $0.10 \pm 0.02 \% /$ ktons (before 1 January 2010) to $0.13 \pm 0.03 \% /$ ktons (after 1 January 2010). Despite the evaluation was conducted for only two sites around the lagoon, the outcomes suggested that the introduction of new "green" fuels after 1 January 2010 did not conduct to a reduction of the impact of ship traffic to metals air concentration in Venice. The contribution to metals concentrations of all the sources identified using PMF for the three sites is shown in the Online Resource (Figure A4).

The evaluation of the SF site was more difficult: PMF could not separate the fossil fuel combustion source from industrial emission. As shown in Fig. 3, the most reasonable solution we could find was characterized by vanadium, nickel (with $\mathrm{V} / \mathrm{Ni}=1.9$ ) and chromium. The other factors were of difficult attribution and were not similar to the sources identified in the other sites. Furthermore, the reconstruction of the model for SF was not satisfactory $\left(\mathrm{R}^{2}=0.54\right)$. For all these 
reasons we preferred not to conduct the source apportionment from the SF dataset. However, PCA identified a component with loadings close to 1 for $\mathrm{V}(0.92)$ and $\mathrm{Ni}$ (0.87) (Online Resource, Table A3), which suggested the presence of a ship traffic source of pollutants. As shown for MAL and PS in Figure A3 (Online Resource), cluster analysis highlighted a high analogy between vanadium and nickel. Overall, the results suggested that a maritime traffic source is present, but its contribution to total metals is not quantifiable, at least with the dataset available.

\section{Contribution of ship traffic to $P M_{10}$ and $P M_{2.5}$}

The primary contribution of ship traffic to $\mathrm{PM}_{10}$, quantified applying equation (2) to data from 2007 to 2013, was 2.5 $\pm 1.0 \%, 1.9 \pm 0.7 \%$ and $2.3 \pm 0.9 \%$ in MAL, PS and SF, respectively. In order to make a comparison with other works in literature the contribution to $\mathrm{PM}_{2.5}$ was also evaluated considering: (i) that the absolute contribution of ship emission to $\mathrm{PM}_{2.5}$ and $\mathrm{PM}_{10}$ is the same; (ii) the experimental $\mathrm{PM}_{2.5} / \mathrm{PM}_{10}$ ratio of 0.78 (2011-2013), calculated for Venice (ARPAV $2014 ; 2013 ; 2012)$. The primary contribution to $\mathrm{PM}_{2.5}$ was $3.3 \pm 1.3 \%$ in MAL, $2.4 \pm 0.9 \%$ in PS and $2.9 \pm 1.1 \%$ in SF. These values are comparable to those obtained by Cesari et al. (2014) for Brindisi (Italy) and Zhao et al. (2013) for Shanghai (China) using the same equation and to other works around the world using PMF (Gibson et al. 2013; Pandolfi et al. 2011). Data of $\mathrm{PM}_{10}$ collected before 2010 were separated from data collected after 1 January 2010 and the contribution was normalized for the ship traffic during the sampling, in order to better compare the two periods. The normalized contribution passed from $15 \pm 6 \%$ /Mtons to $10 \pm 4 \%$ /Mtons in MAL, from $8 \pm 3 \%$ /Mtons to $7 \pm 3 \%$ /Mtons in PS and from $12 \pm 5 \%$ /Mtons to $7 \pm 3 \%$ /Mtons in SF (Fig. 2c). With the exception of PS, a decrease in the contribution of the maritime traffic to $\mathrm{PM}_{10}$ was observed. These results are comparable to a previous work, conducted in Venice (Contini et al. 2015): here, the primary contribution of ship traffic to $\mathrm{PM}_{2.5}$, calculated from high-resolution data and normalized by the average daily ship traffic, decreased from 15 $\pm 3 \%$ day/Mtons in 2009 to $9 \pm 3 \%$ day/Mtons in 2012, giving more forcefulness to our outcomes. As Contini et al. (2015) hypothesized, it seems that the use of low-sulphur fuels could be an efficient method to reduce the primary impact of shipping on aerosol at local scale.

\section{Conclusions}

The Venice lagoon area was studied in order to quantify the impact of maritime traffic on various pollutants, not directly included in the European shipping emissions regulation: polycyclic aromatic hydrocarbons, metals and particulate matter.
The quantification was conducted using different state-of-the-art methodologies, starting from data collected between 2007 (or 2009) and 2012, which allowed us to evaluate the effect of the implementation of the European Directive 2005/33/EC, entered in force in 2010 . The results obtained by separating data collected before and after 1 January 2010 showed that the normalized contribution of ship traffic to primary particulate matter decreased in two sites over three, passing from $15 \pm 6 \%$ /Mtons to $10 \pm 4 \%$ /Mtons in MAL, from $8 \pm 3 \%$ /Mtons to $7 \pm 3 \%$ /Mtons in PS and from 12 $\pm 5 \%$ /Mtons to $7 \pm 3 \%$ /Mtons in SF. Focusing on the other pollutants we obtained different results. Despite the number of analyzed samples is limited, we observed a small reduction in the contribution of the harbour sector to gaseous PAHs (from $74 \%$ /Mtons in 2009 to $63 \%$ /Mtons in 2012), but stable value (around $52 \% /$ Mtons) for particulate PAHs. The normalized contribution of ship traffic to metals in $\mathrm{PM}_{10}$, calculated as the contribution of the fossil fuel combustion factor obtained using PMF, was stable (around $0.12 \% / \mathrm{ktons}$ ) in MAL and even increased in PS from $0.1 \pm 0.02 \% /$ ktons before 1 January 2010 to $0.13 \pm 0.03 \% /$ ktons after 1 January 2010 . The outcomes suggest that legislation on ship traffic, which focused on the issue of the emissions of sulphur oxides, could be an efficient method to also reduce the impact of shipping on particulate matter concentration; on the other hand, we did not observe a significant reduction on PAHs and metals.

Acknowledgments This work was supported by the POSEIDON project (Pollution monitoring of ship emissions: an integrated approach for harbours of the Adriatic basin), grant 1 M-MED14-12, funded by ERDF funds and National sources within the framework of MED program 2007-2013; it was also supported by the Venice Port Authority and the "Ministero delle Infrastrutture e dei Trasporti-Provveditorato Interregionale per le Opere Pubbliche del Veneto-Trentino Alto AdigeFriuli Venezia Giulia" (Italian Ministry of Infrastructures and Transports) through its dealer Consorzio Venezia Nuova. The authors wish to thank CORILA (Consortium for Managing the Research Activities Concerning the Venice Lagoon System) for the valuable assistance and logistic support during the sampling campaigns. The authors wish to thank the Regional Agency for Prevention and Protection of Environment of Veneto (ARPAV) for providing some of the chemical data used in this work. Authors also wish to thank Angela Maria Stortini, Silvia De Pieri, Elena Argiriadis and Italo Ongaro (Ca' Foscari University of Venice) for their help in sampling and analysis.

\section{Compliance with ethical standards}

Conflict of interest The authors declare that they have no competing interests.

Funding This study was funded by the POSEIDON project (POllution monitoring of Ship Emissions: an IntegrateD approach for harbOurs of the Adriatic basiN), grant 1M-MED14-12, funded by ERDF funds and National sources within the framework of MED program 2007-2013; it was also supported by the Venice Port Authority and the "Ministero delle Infrastrutture e dei Trasporti-Provveditorato Interregionale per le Opere Pubbliche del Veneto-Trentino Alto Adige-Friuli Venezia Giulia" (Italian Ministry of Infrastructures and Transports) through its dealer Consorzio Venezia Nuova. CORILA (Consortium for Managing the Research 
Activities Concerning the Venice Lagoon System) provided valuable assistance and logistic support during the sampling campaigns; the Regional Agency for Prevention and Protection of Environment of Veneto (ARPAV) provided some of the chemical data used in this work.

\section{References}

Agrawal H, Eden R, Zhang X et al (2009) Primary particulate matter from ocean-going engines in the Southern California Air Basin. Environ Sci Technol 43:5398-5402. doi:10.1021/es8035016

ARPAV (2014) Relazione regionale della qualità dell'aria - Anno di riferimento: 2013

ARPAV (2013) Relazione regionale della qualità dell'aria - Anno di riferimento: 2012

ARPAV (2012) Relazione regionale della qualità dell'aria - Anno di riferimento: 2011

Cesari D, Genga A, Lelpo P et al (2014) Source apportionment of PM2.5 in the harbour-industrial area of Brindisi (Italy): Identification and estimation of the contribution of in-port ship emissions. Sci Total Environ 497-498:392-400. doi:10.1016/j.scitotenv.2014.08.007

Cincinelli A, Del Bubba M, Martellini T et al (2007) Gas-particle concentration and distribution of n-alkanes and polycyclic aromatic hydrocarbons in the atmosphere of Prato (Italy). Chemosphere 68: 472-478. doi:10.1016/j.chemosphere.2006.12.089

Contini D, Gambaro A, Donateo A et al (2015) Inter-annual trend of the primary contribution of ship emissions to PM2.5 concentrations in Venice (Italy): efficiency of emissions mitigation strategies. Atmos Environ 102:183-190. doi:10.1016/j.atmosenv.2014.11.065

Contini D, Belosi F, Gambaro A et al (2012) Comparison of PM10 concentrations and metal content in three different sites of the Venice Lagoon: an analysis of possible aerosol sources. J Environ Sci (China) 24:1954-1965. doi:10.1016/S1001-0742(11)61027-9

Donateo A, Gregoris E, Gambaro A et al (2014) Contribution of harbour activities and ship traffic to PM2.5, particle number concentrations and PAHs in a port city of the Mediterranean Sea (Italy). Environ Sci Pollut Res 21:9415-9429

ECG (2014) Sulphur content in marine fuels - briefing report., http:// www.ecgassociation.eu/Portals/0/Documentation/Publications/ ECGBriefingReport_SulphurContent_Jan2013.pdf. Accessed 25 August 2015

EEA (2013) The impact of international shipping on European air quality and climate forcing., http://www.eea.europa.eu/publications/theimpact-of-international-shipping. Accessed 25 August 2015
Gibson MD, Pierce JR, Waugh D et al (2013) Identifying the sources driving observed PM2.5 temporal variability over Halifax, Nova Scotia, during BORTAS-B. Atmos Chem Phys 13:7199-7213. doi:10.5194/acp-13-7199-2013

Gregoris E, Argiriadis E, Vecchiato M et al (2014) Gas-particle distributions, sources and health effects of polycyclic aromatic hydrocarbons (PAHs), polychlorinated biphenyls (PCBs) and polychlorinated naphthalenes (PCNs) in Venice aerosols. Sci Total Environ 476-477:393-405

Hassan SK, Khoder MI (2012) Gas-particle concentration, distribution, and health risk assessment of polycyclic aromatic hydrocarbons at a traffic area of Giza, Egypt. Environ Monit Assess 184:3593-3612. doi:10.1007/s10661-011-2210-8

Henry RC, Lewis CW, Hopke PK, Williamson HJ (1984) Review of receptor model fundamentals. Atmos Environ 18:1507-1515. doi: 10.1016/0004-6981(84)90375-5

IMO (2015a) Summary of status of convention., http://www.imo.org/ About/Conventions/StatusOfConventions/Pages/Default.aspx. Accessed 25 August 2015

IMO (2015b) Special areas under MARPOL., http://www.imo.org/ OurWork/Environment/SpecialAreasUnderMARPOL/Pages/ Default.aspx. Accessed 25 August 2015

Pandolfi M, Gonzalez-Castanedo Y, Alastuey A et al (2011) Source apportionment of PM10 and PM2.5 at multiple sites in the strait of Gibraltar by PMF: impact of shipping emissions. Environ Sci Pollut Res 18:260-269. doi:10.1007/s11356-010-0373-4

Piazza R, Gambaro A, Argiriadis E et al (2013) Development of a method for simultaneous analysis of PCDDs, PCDFs, PCBs, PBDEs, PCNs and PAHs in Antarctic air. Anal Bioanal Chem 405:917-932. doi: 10.1007/s00216-012-6464-y

Rampazzo G, Masiol M, Visin F et al (2008) Geochemical characterization of PM10 emitted by glass factories in Murano, Venice (Italy). Chemosphere 71:2068-2075. doi:10.1016/j.chemosphere.2008.01. 039

Schembari C, Cavalli F, Cuccia E et al (2012) Impact of a European directive on ship emissions on air quality in Mediterranean harbours. Atmos Environ 61:661-669. doi:10.1016/j.atmosenv.2012.06.047

Thurston GD, Spengler JD (1985) A quantitative assessment of source contributions to inhalable particulate matter pollution in metropoli$\tan$ Boston. Atmos Environ 19:9-25. doi:10.1016/0004-6981(85) 90132-5

Viana M, Amato F, Alastuey A et al (2009) Chemical tracers of particulate emissions from commercial shipping. Environ Sci Technol 43: 7472-7477. doi:10.1021/es901558t

Zhao M, Zhang Y, Ma W et al (2013) Characteristics and ship traffic source identification of air pollutants in China's largest port. Atmos Environ 64:277-286. doi:10.1016/j.atmosenv.2012.10.007 